\title{
Selection for morphology, gaits and functional traits in Lusitano horses: I. Genetic parameter estimates
}

\author{
A.A. Vicente ${ }^{\mathrm{a}, \mathrm{b}, \mathrm{c}}$, N. Carolino ${ }^{\mathrm{b}, \mathrm{d}}$, J. Ralão-Duarte ${ }^{\mathrm{e}}$, L.T. Gama ${ }^{\mathrm{c}, *}$ \\ a Escola Superior Agrária do Instituto Politécnico de Santarém, Apartado 310, 2001-904 Santarém, Portugal \\ ${ }^{\mathrm{b}}$ Unidade Estratégica de Investigação e Serviços de Biotecnologia e Recursos Genéticos, INIAV, IP 2005-048 Vale de Santarém, Portugal \\ c CIISA - Faculdade de Medicina Veterinária, Universidade de Lisboa, 1300-477 Lisboa, Portugal \\ d Escola Universitária Vasco da Gama, Estrada da Conraria, 3040-714 Coimbra, Portugal \\ e Associação Portuguesa de Criadores do Cavalo Puro-sangue Lusitano - APSL, Av. Mem Ramires, 94, 2765-337 Estoril, Portugal
}

\section{A R T I C L E I N F O}

Keywords:

Heritability

Phenotypic correlation

Genetic correlation

Selection index

Dressage

Working equitation

\begin{abstract}
A B S T R A C T
Genetic parameters were estimated for morphology, gaits and functional traits in Lusitano horses by uni- and multivariate animal models. Morphological traits considered in the analyses were partial scores attributed to up to 18,076 horses at the time of registration in the studbook and included head and neck, shoulder and withers, chest and thorax, back and loin, croup, legs and overall impression, plus a final score computed by summing the partial morphological scores and the gaits score. The functional traits considered were the scores obtained in the dressage and maneability trials of working equitation (WE, about 1500 records by 200 horses), and classical dressage (12,131 records by 759 horses). The heritability $\left(h^{2}\right)$ estimates for all partial morphological scores ranged between 0.12 and 0.18 , except for legs (0.07). The $h^{2}$ for final score, height at withers and gaits was $0.18,0.61$ and 0.17, respectively, while for WE dressage trial and classical dressage it was 0.32 and for WE maneability trial it was 0.18 . The genetic correlations $\left(r_{G}\right)$ of final score with the different partial scores were generally high (0.56-0.95), while among partial components of morphology they were positive but widely different $(0.08-0.77)$. With the exception of legs, $r_{G}$ between morphology/gaits and functional traits were positive, with a stronger relationship between morphological traits and performance in WE dressage trial $\left(r_{G}\right.$ between 0.36 and 0.56 ) when compared with performance in maneability trial or classical dressage. Height at withers had a $r_{G}$ of 0.40 with performance in classical dressage, but lower $r_{G}(0.06$ and -0.10$)$ with WE trials. Final score and overall impression had moderate to strong genetic relationships with functional traits, especially with WE dressage trial, while gaits had a strong $r_{G}$ with performance in all the disciplines (0.60-0.72). Indirect selection for morphology/gaits to improve functionality was assessed, by selecting for final score or a combined index of partial scores. Compared to direct selection for functionality, selection for final score or an index combining partial morphological scores would be less effective, resulting in accuracies of, respectively, 0.28 and 0.37 for WE dressage trial, 0.14 and 0.38 for WE maneability trial and 0.22 and 0.39 for classical dressage. Thus, an index combining all partial morphological scores would be better than selection for overall final score, but its relative efficiency compared to direct selection would be about 0.7 in WE dressage trial and classical dressage, and 0.9 in WE maneability trial. Lusitano horses maintain considerable levels of genetic variability, and selection for both morphology and functionality should be effective. The favorable genetic relationships existing between morphology and performance indicate that morphology/gaits traits can play an important role in a two-stage selection program, contributing to enhance selection
\end{abstract}

\footnotetext{
* Corresponding author. Tel.: +351 213652800; fax: +351 213652889.

E-mail address: Itgama@fmv.ulisboa.pt (L.T. Gama).
} 
response when the genetic improvement of working equitation or classical dressage is intended.

(c) 2014 Elsevier B.V. All rights reserved.

\section{Introduction}

Lusitano is the major equine breed in Portugal and a popular riding horse in many other countries, with nearly 5000 breeding mares registered around the world (Vicente et al., 2012). In the past, Lusitano horses were selected, as other breeds known as "Baroque horses", according to the Renaissance model for classical riding, where harmony, rider submission and "haute école" were of outmost importance. Nevertheless, in the case of Lusitano, horses always remained attached to human activities, including bullfighting, herd management, carriage-pulling, cavalry, etc., and they were also selected for these purposes, in addition to selection for morphology and gaits (Bowling and Ruvinsky, 2000; Gonzaga, 2004).

The current regulations of the Lusitano studbook establish that, to be registered, males and females must be graded by a jury, and classified according to their adherence to breed standard, morphological features and gaits (APSL, 2010). Registered horses are later used, e.g., for leisure, bullfighting, and showjumping, and some are used in dressage and working equitation (WE).

The first step of a breeding program is the definition of breeding objectives, which is not easy in breeds with high versatility such as Lusitano, where selection is aimed at multiple purposes and both morphological and functional traits are often considered. Of crucial importance in the success of the breeding program is the existence of genetic variability for the traits of interest. Heritability estimates for conformation traits in several horse breeds were reviewed by Stock and Distl (2006), and genetic parameters for performance in dressage events have been reported, e.g., by Ricard et al. (2000) and Stewart et al. (2010). However, information is scarce on the genetic relationships among morphology, gaits and functionality (Ducro et al., 2007; Koenen et al., 1995; Sánchez et al., 2013; Wallin et al., 2003).

In this work, information collected over the years in Lusitano horses was used to: (a) estimate genetic parameters for morphology, gaits, height at withers and performance in dressage and working equitation and (b) appraise the usefulness of an index combining morphology and gaits as an early selection criterion of functionality.

\section{Materials and methods}

This work was carried out with pedigree data made available by Fundação Alter Real (Portuguese National Stud) and the Portuguese Association of Lusitano Horse Breeders (Associação Portuguesa de Criadores do Cavalo Puro-Sangue Lusitano, APSL). In addition to pedigree information, APSL provided records on the scores given to purebred animals when they are evaluated to be registered in the Breeders Section of the studbook. Records on sports' events (dressage and working equitation) for animals competing in Portugal were obtained from the Portuguese Equestrian Federation (Federação Equestre Portuguesa), and those for Lusitano horses competing abroad were obtained from the International Equestrian Federation (FEI) or from other national federations.

\subsection{Pedigree information}

The pedigree information registered in the studbook database includes animals born since 1824. After 1992, all the animals have their parentage confirmed by genetic markers before registration. After editing and validation, the pedigree database included records on 53,417 horses born up until 2009.

\subsection{Morphology and gaits scores}

In the breeding scheme of Lusitano horses, all candidates to be registered as sires and dams are submitted to a morpho-functional evaluation once before they are accepted in the Breeders Section of the studbook at a minimum age of three years. This evaluation of gaits and morphology consists of a classification by a jury of three experts, but the combination of judges differs from one grading event to another. Throughout the period analyzed, the grading system was always the same, and 25 different judges were involved in the classification of Lusitano horses. These judges are trained and recycled by APSL on a yearly basis, and licensed to classify animals all over the world. A reduced number of common judges is involved in events worldwide, to ensure the adoption of analogous classification criteria.

The judges give marks in a scale of 0-10 to eight partial items related to conformation and gaits, and these partial scores are intended to reflect how close the animal is to what is considered the ideal standard for the breed (Table 1). The morphological traits scored are head and neck (HN), shoulder and withers (SW), chest and thorax $(\mathrm{CT})$, back and loin (BL), croup (CR), legs (LE), overall impression (OI) and gaits (GA). A final score (FS) ranging between 0 and 100 points is then computed by summing the partial scores, which receive coefficient weights of either 1.5 (BL, LE, OI and GA) or 1.0 (HN, SW, CT and CR), as outlined in Tables 1 and 2 . The score kept by the studbook and analyzed in our work was the mean classification attributed by the three judges that made-up the jury. Nevertheless, the score attributed by the jury to each morphology component may not have the same variability, such that the jury could, e.g., use a wider scale for HN and a narrower scale for LE. If that is the case, the variability in FS would reflect not only the coefficient weights applied to the various morphology components, but also the variability of the scores attributed to each one 
Table 1

Summary description of the scoring system used in the Breeders Section of Lusitano horse studbook registration. Adapted from APSL (2010).

\begin{tabular}{|c|c|}
\hline Trait & Definition \\
\hline Head and neck (HN) & $\begin{array}{l}\text { Well-proportioned head of medium length, with a sub-convex profile and big and confident eyes. Arched neck with a broad } \\
\text { base and a narrow junction to the head }\end{array}$ \\
\hline $\begin{array}{l}\text { Shoulder and withers } \\
\text { (SW) }\end{array}$ & Well defined withers with smooth transition to the neck. Long, oblique and muscular shoulders \\
\hline Chest and thorax $(\mathrm{CT})$ & Deep and muscular chest, with a well-developed ribcage, with an oblique insertion in the spine \\
\hline Back and loin (BL) & Horizontal back with a smooth attachment to the withers and loin. Short, broad and well-muscled loin \\
\hline Croup (CR) & Strong, round, well-proportioned and slightly oblique \\
\hline Legs (LE) & Legs harmoniously muscled with good definition of joints and tendons. Correct conformation and balance of front and hind legs \\
\hline Overall impression & Adherence to breed standard and score of overall forms \\
\hline Gaits (GA) & Agile, high stepping and forward thrusting, gentle and easy to ride \\
\hline Final score (FS) & $\begin{array}{l}\text { Sum of the eight partial scores for morphology and gaits, obtained by weighing partial scores for BL, LE, OI and GA by a factor of } \\
1.5 \text {, and other partial scores by } 1.0\end{array}$ \\
\hline $\begin{array}{l}\text { Height at withers } \\
\text { (HW) }\end{array}$ & Height at the highest point of the withers, measured with vertical pole equipped with a line scale \\
\hline
\end{tabular}

Table 2

Descriptive statistics and path coefficients for morphology and gaits traits in Lusitano horses.

\begin{tabular}{|c|c|c|c|c|c|c|c|}
\hline Trait $^{\mathrm{a}}$ & $\mathrm{NR}^{\mathrm{b}}$ & Mean $\pm \mathrm{SD}^{\mathrm{c}}$ & Range (min/max) & $\mathrm{CV}^{\mathrm{d}}(\%)$ & $\begin{array}{l}\text { Weight in } \\
\text { final score }\end{array}$ & $\beta_{\mathrm{FS} \cdot \mathrm{X}}{ }^{\mathrm{e}}$ & $\operatorname{RC}^{\mathrm{f}}(\%)$ \\
\hline Head and neck (HN) & 17,139 & $7.24 \pm 0.81$ & $4 / 10$ & 11.12 & 1.0 & 0.180 & 10.7 \\
\hline Shoulder and withers (SW) & 17,139 & $7.47 \pm 0.62$ & $5 / 10$ & 8.28 & 1.0 & 0.142 & 7.9 \\
\hline Chest and thorax (CT) & 17,139 & $7.48 \pm 0.67$ & $4 / 10$ & 8.97 & 1.0 & 0.142 & 8.4 \\
\hline Back and loin (BL) & 17,139 & $6.93 \pm 0.73$ & $4 / 10$ & 10.46 & 1.5 & 0.238 & 15.5 \\
\hline Croup (CR) & 17,139 & $7.29 \pm 0.71$ & $4 / 10$ & 9.70 & 1.0 & 0.160 & 9.6 \\
\hline Legs (LE) & 17,139 & $6.68 \pm 0.69$ & $4 / 10$ & 10.28 & 1.5 & 0.217 & 12.8 \\
\hline Overall impression (OI) & 17,139 & $7.17 \pm 0.71$ & $4 / 10$ & 9.94 & 1.5 & 0.232 & 16.7 \\
\hline Gaits (GA) & 17,139 & $7.27 \pm 0.78$ & $4 / 10$ & 10.72 & 1.5 & 0.247 & 18.4 \\
\hline Final score (FS) & 18,076 & $71.39 \pm 4.94$ & $44.5 / 97.0$ & 6.92 & - & - & - \\
\hline Height at withers (HW) & 16,955 & $157.80 \pm 4.05$ & $140.0 / 178.0$ & 2.56 & - & - & - \\
\hline
\end{tabular}

a Morphological partial scores and gaits measured in a scale of 0-10 points; final score measured in a scale of 0-100 points; height at withers in cm.

${ }^{\mathrm{b}}$ Number of records.

c Standard deviation.

${ }^{\mathrm{d}}$ Coefficient of variation.

${ }^{\mathrm{e}} \beta_{\mathrm{FS} . \mathrm{x}}$, standard partial regression coefficient of final score (FS) on each morphology and gaits item (X).

${ }^{\mathrm{f}} \mathrm{RC}$, relative percentage contribution to the variability of final score.

of them. Therefore, to assess the actual weight contributed by each morphology component to the variability of final scores, a path analysis ( $\mathrm{Li}, 1975$ ) was performed, using the TCALIS procedure of SAS (2004).

In the grading of morphology and gaits, when sires are judged, they must be ridden by a horseman, and they are scored on gaits and conformation in public events gathering animals from different studs. On the other hand, fewer restrictions exist regarding the classification of mares, and they can be presented to the jury either mounted, in-hand or at liberty. In addition, at the time of classification all animals are measured for height at withers (HW), and a digital photo is taken and stored in the database.

The original morphology data set included records on 18,892 animals classified in the period of 1967-2009. Given the depth of the pedigree (mean of about 10 complete equivalent generations known) and the high genetic relationship existing in the breed, nearly all animals had parents known and the studs were well connected (Vicente et al., 2012). Records were edited to exclude those obtained before three years of age, and some cases where only one record was available in a given stud or year of classification. After editing, the data set included final conformation and gaits scores for 18,076 animals (5283 stallions and 12,793 mares), from 904 different studs. These horses were born throughout the world, with about 2/3 born in Portugal and the remaining abroad.

\subsection{Functional traits}

In the data set analyzed, information was available on the scores obtained by registered Lusitano horses in classical dressage and working equitation events, both in Portugal and abroad (mainly, in events taking place in Spain, France and Brazil). Generally speaking, classical dressage emphasizes the natural athletic ability of the horse and his willingness to perform in a smooth and effort-free manner, with impulsion, rhythm and suppleness (FEI, 2013). On the other hand, working equitation is a novel discipline created in 1996 , which aims at promoting competition between different ways of riding used in the fieldwork in various countries, and horses are submitted to four different competition tests, which are called "trials" 
Table 3

Descriptive statistics for functional traits in Lusitano horses.

\begin{tabular}{|c|c|c|c|c|c|c|c|c|c|}
\hline \multirow[t]{2}{*}{ Trait } & \multicolumn{5}{|c|}{ Records } & \multicolumn{4}{|c|}{ Fixed effects } \\
\hline & $\mathrm{NR}^{\mathrm{a}}$ & $N A^{b}$ & Mean $\pm \operatorname{SD}^{\mathrm{c}}(\%)$ & $\begin{array}{l}\text { Range (\%) } \\
(\min / \max )\end{array}$ & $\mathrm{CV}^{\mathrm{d}}(\%)$ & $\mathrm{NE}^{\mathrm{e}}$ & $\mathrm{CL}^{\mathrm{f}}$ & $\begin{array}{c}\text { Age } \\
\text { mean } \pm \mathrm{SD}^{\mathrm{c}}(\mathrm{m})\end{array}$ & $\begin{array}{c}\text { Inbreeding } \\
\text { mean } \pm \operatorname{SD}^{\mathrm{C}}(\%)\end{array}$ \\
\hline Working equitation dressage trial & 1454 & 186 & $60.90 \pm 7.56$ & $24.02 / 79.26$ & 12.41 & 109 & 5 & $103.56 \pm 31.95$ & $11.52 \pm 9.24$ \\
\hline Working equitation maneability trial & 1524 & 211 & $61.25 \pm 10.42$ & $25.63 / 85.83$ & 17.01 & 110 & 5 & $103.86 \pm 32.40$ & $11.36 \pm 9.15$ \\
\hline Classical dressage & 12,131 & 759 & $62.74 \pm 4.47$ & $37.00 / 89.60$ & 7.13 & 1379 & 11 & $110.28 \pm 40.20$ & $8.13 \pm 6.26$ \\
\hline $\begin{array}{l}\text { a Number of records. } \\
\text { b Number of animals. } \\
{ }^{c} \text { Standard deviation. } \\
{ }^{d} \text { Coefficient of variation. } \\
\text { e Number of events. } \\
{ }^{\mathrm{f}} \text { Number of competition levels. }\end{array}$ & & & & & & & & & \\
\hline
\end{tabular}

by the World Association for Working Equitation. These are the dressage test, ease of handling (maneability), speed and cow separation trials (WAWE, 2013a). Dressage and working equitation events are classified into different levels of competition difficulty, and in our study eleven levels were recognized for dressage and five levels for working equitation. These levels are ranked according to the criteria adopted by national federations and the International Equestrian Federation (FEI), which are function of the difficulty of the test, age of the horse and seniority of the rider.

In our study, we used functional records collected between 2000 and 2012, including information on 12,569 dressage scores and 1575 working equitation scores. These records were edited to ensure that at least two Lusitano horses were represented in the same event and competition level. After editing, 12,131 records by 759 animals were available for classical dressage events (Table 3). For working equitation, the edited data set included 1454 records by 186 horses for the dressage trial and 1524 records by 211 horses for the maneability trial. The two other trials which are part of working equitation were not included in our study, because the cow separation trial is only performed in international championships, and thus was only available for very few animals, and the results of the speed trial are converted into a scoring system which is not consistent from event to event.

The dressage and working equitation results analyzed in our study are the scores obtained by a horse in a given event, which generally included horses of other breeds in addition to Lusitano. These scores were given in a scale of $0-100$ and correspond to the mean classification attributed by a jury of 3-5 judges. For the purposes of our analyses, an event was considered to correspond to the combination of place and date of a dressage or working equitation competition.

\subsection{Statistical analyses}

Data were analyzed by mixed models, and genetic parameters were estimated by restricted maximum likelihood with the MTDFREML software (Boldman et al., $1995)$ iterating until a convergence criterion of $10^{-12}$ was obtained. The animal model (AM) used in the analyses of morphological data included the fixed effects of stud $(n=904)$, year of classification $(n=43)$ and sex, plus the linear effect of inbreeding and the linear and quadratic effect of age at scoring as covariables. The additive genetic effect of the animal was the only random effect considered for morphological traits. The number of animals in the numerator relationship matrix, including base animals, was 21,480 .

For dressage and working equitation data, an AM with repeated records was used, including the fixed effects of sex, event and level of competition, plus the linear effect of inbreeding and the linear and quadratic effects of age at competition as covariables. The random effects included in the analyses of functional data were the additive genetic effect of the animal plus its permanent environmental effect.

All traits were first investigated by univariate analyses in MTDFREML, to obtain preliminary estimates of variance components. After convergence was reached, breeding values were predicted for all animals in the relationship matrix, and estimates of fixed effects were obtained. Afterwards, bivariate analyses were carried out among combinations of the different morphological traits using MTDFREML and the same linear models used in univariate analyses, to obtain estimates of the corresponding genetic and phenotypic correlations.

To guarantee that the genetic parameters obtained in different trait combinations were consistent, i.e., to ensure that their covariance matrix was positive semi-definite, a multivariate analysis including all the 10 morphological traits was also carried out with the VCE software - version 6.0.2 (Groeneveld et al., 2010).

Finally, different bivariate analyses were carried out, including morphology and gaits on one side and functional data on the other, to obtain estimates of the genetic correlation between each of the morphology and gait traits and the results obtained in the dressage and maneability trials of working equitation, and in classical dressage. In this case, functional information could be collected in the same animal several times during its life, while morphology scoring is performed only once. Therefore, the environmental and phenotypic correlations between morphology and functionality are meaningless in our data set, 
but genetic correlations are important and useful, and these were reported for the different trait combinations.

The standard errors of genetic correlations among partial morphological traits were obtained directly from the MTDFREML analyses, but for the correlations between other morphological or functional traits the standard errors could not be obtained in this way, because of the different numbers of animals in the two sets of data. For the latter combinations, standard errors of genetic correlations were computed as described by Falconer and MacKay (1996).

\subsection{Index selection}

The usefulness of morphology and gaits indicators in indirect selection for functionality was investigated by standard index selection procedures (Hazel, 1943; Van Vleck, 1993). First, the possibility of improving functionality by selecting indirectly for final score was assessed, and the accuracy resulting in the three functional traits considered in our analysis was compared with the accuracy obtained with the direct selection for these traits, assuming that only one record is available per animal. Then, based on the estimated phenotypic relationship between morphology and gait traits, and their estimated genetic relationship with each of the functional traits, the possibility of selecting based on an index combining all the morphology and gait traits was investigated. In this case, final score was excluded from the analyses because all its components were being considered in the index. In matrix notation, the weights to be applied in the selection index combining individual partial scores were obtained as follows:

$b=P^{-1} g$

where $b$ is the vector of weights to be applied to each of the morphology and gait traits, $P$ is the phenotypic (co) variance matrix of morphological traits (excluding final score), and $g$ is the vector of genetic covariances of the morphology and gait traits with each of the functional traits considered.

After solving for $b$, the variance of the selection index was obtained as follows:

$\sigma_{I}^{2}=b^{\prime} P b$

and the accuracy of selection for the ith functional trait was estimated as follows:

$r_{A P i}=\sqrt{\frac{\sigma_{I}^{2}}{\sigma_{A i}^{2}}}$

where $r_{A P i}$ is the accuracy obtained from indirect selection for the $i$ th trait and $\sigma_{A i}^{2}$ is the corresponding additive genetic variance for this trait.

The relative weight given to each of the morphology and gait traits included in the selection index was assessed by constructing a reduced selection index where the morphological trait is removed, and calculating the reduction observed in accuracy relative to the optimum index (Cameron, 1997).
The derivation of selection index weights and the corresponding matrix operations were carried out with the IML procedure of SAS (2004).

\section{Results}

The number of animals recorded for morphological traits ranged between 16,995 for HW and 18,076 for FS (Table 2). Overall, the means for the partial scores ranged mostly from 7.17 for OI to 7.48 for CT, with the exception of BL and especially LE, which had means of 6.93 and 6.68, respectively. The global mean FS was $71.39 \pm 4.94$ points, and it was higher by about 2 points in females (Fig. 1a), while for HW the global mean was $157.80 \pm 4.05 \mathrm{~cm}$, with a superiority of about $2.8 \mathrm{~cm}$ in sires (Fig. 1b).

The proportional influence of each morphological component on the variability of FS was assessed using path coefficients analyses (Table 2). Of the traits which were assigned a weight of 1.0 , the $\mathrm{HN}$ and $\mathrm{CR}$ had a contribution to FS close to that which was initially anticipated, while the SW and CT had a much lower than expected contribution to FS. On the other hand, the partial traits assigned an emphasis of 1.5 had indeed a higher impact upon the FS, but in the case of GA and OI the actual weight was about 18.4 and $16.7 \%$, respectively, while for LE the weight was below $13 \%$. Taken together, these results indicate that the scale adopted by the studbook is not being consistently applied to the different partial traits, and the variability in final score does not necessarily reflect the intended weights assigned to each partial component.

For functional traits, the mean scores for the two trials of working equitation were about $61 \%$ (Table 3 ), but the variability of the scoring marks was much higher for maneability than for dressage trial (Table 3 and Fig. 1c). When compared with the two working equitation trials, the results in classical dressage showed a slightly higher mean score, but a CV which was nearly one-half (Table 3 and Fig. 1d).

For the partial scores, the largest estimate of additive genetic variance was obtained for $\mathrm{HN}$, which also had the largest phenotypic variance (Table 4), while the smallest estimate of genetic variance was obtained for LE.

With the exception of LE, the heritability $\left(h^{2}\right)$ estimates for all partial morphological scores ranged between 0.12 and 0.18 , tending to be slightly higher for $\mathrm{HN}$ and GA. On the other hand, the estimated $h^{2}$ was 0.07 for the score of LE. The estimated $h^{2}$ was 0.18 for the FS computed from the weighted sum of the partial scores, and 0.61 for the more objective measure of HW. For all estimates of $h^{2}$, the SE was between 0.012 and 0.015 , indicating a good reliability of the estimated parameters.

Large differences were observed in both the variance components and ratios for the three functional traits analyzed (Table 5), with the largest phenotypic variance observed in the maneability trial of working equitation, and the smallest for classical dressage, as reflected also in Fig. 1c and d. The additive genetic variance was similar for both trials of working equitation, and much higher than that estimated for classical dressage. A similar pattern was observed for the permanent environmental component of variance, which was lowest for classical dressage. 
a

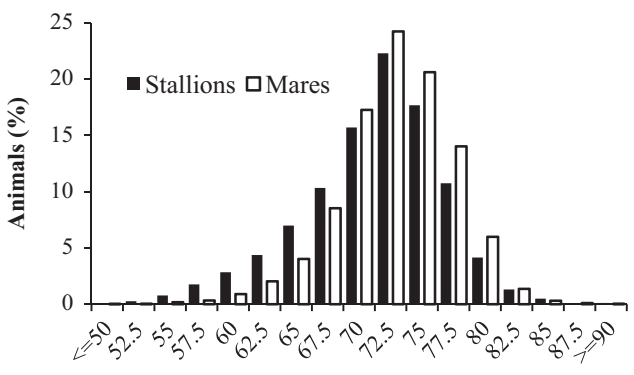

Final Score (points)

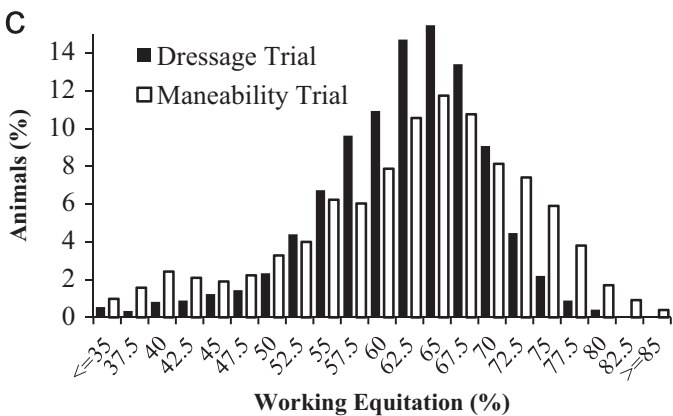

b

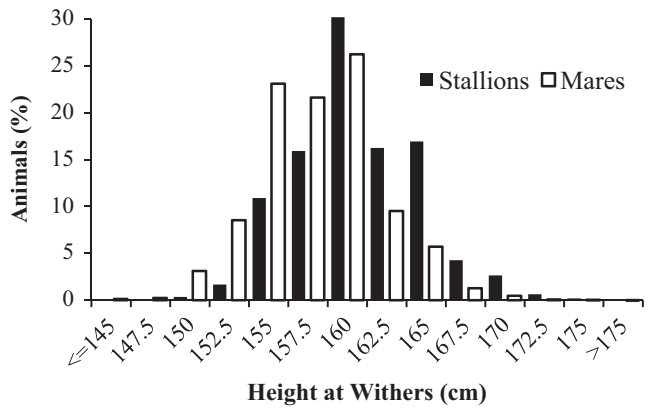

d

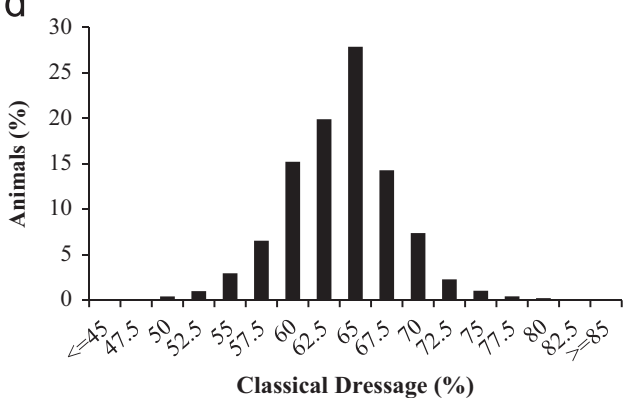

Fig. 1. Distribution of records in Lusitano horses for: (a) final score in stallions and mares; (b) height at withers in stallions and mares; (c) scores for dressage and maneability trials in working equitation; and (d) scores for classical dressage.

Table 4

Estimated genetic $\left(\hat{\sigma}_{a}^{2}\right)$ and phenotypic $\left(\hat{\sigma}_{p}^{2}\right)$ variances and heritability $\left(h^{2}\right)$ with associated standard error (SE) for gaits and morphological traits in Lusitano horses, obtained from univariate analyses.

\begin{tabular}{lrrr}
\hline Trait & $\hat{\sigma}_{a}^{2}$ & $\hat{\sigma}_{p}^{2}$ & $h^{2} \pm \mathrm{SE}$ \\
\hline Head and neck (HN) & 0.1021 & 0.5737 & $0.18 \pm 0.015$ \\
Shoulder and withers (SW) & 0.0471 & 0.3601 & $0.13 \pm 0.014$ \\
Chest and thorax (CT) & 0.0437 & 0.3579 & $0.12 \pm 0.014$ \\
Back and loin (BL) & 0.0705 & 0.4525 & $0.16 \pm 0.015$ \\
Croup (CR) & 0.0666 & 0.4576 & $0.15 \pm 0.015$ \\
Legs (LE) & 0.0249 & 0.3697 & $0.07 \pm 0.012$ \\
Overall impression (OI) & 0.0584 & 0.4253 & $0.14 \pm 0.014$ \\
Gaits (GA) & 0.0813 & 0.4875 & $0.17 \pm 0.015$ \\
Final score (FS) & 3.2387 & 18.1342 & $0.18 \pm 0.015$ \\
Height at withers (HW) & 8.8781 & 14.4707 & $0.61 \pm 0.015$ \\
\hline
\end{tabular}

The estimated $h^{2}$ was similar for the dressage trial of working equitation and for classical dressage $\left(h^{2}=0.32\right.$, Table 5), and the estimated repeatability $\left(r_{e}\right)$ did not differ much for the two equestrian disciplines $\left(r_{e}=0.67\right.$ and 0.60 , respectively). For the maneability trial, however, the estimated $h^{2}$ was lower $\left(h^{2}=0.18\right)$, mainly due to the large phenotypic variance for this trait, but the estimated proportional contribution of permanent environmental variance $\left(c^{2}=0.28\right)$ was similar to that observed for classical dressage (Table 5). In the analyses of functional traits, the SE of $h^{2}$ were in the range of $0.075-0.171$, much higher than those observed for morphological traits, reflecting the much smaller sample size used, especially for working equitation.

The phenotypic correlations $\left(r_{P}\right)$ between FS and the different partial scores were positive and strong, ranging from about 0.56 for SW to 0.80 for OI (Table 6). Among the partial morphological components, the $r_{P}$ were positive and generally intermediate, ranging between about 0.20 and 0.57 . The GA had $r_{P}$ consistently in the range of about 0.30 and 0.40 with the other morphological components, with no indication that it would be stronger with LE, as could perhaps be anticipated. The HW had low to moderate positive phenotypic correlations with the morphology partial components, with lowest values for LE and HN and highest for SW and CT, with an estimated correlation of about 0.2 between HW and FS.

The genetic correlations $\left(r_{G}\right)$ of FS with the different partial scores were generally high, ranging from about 0.56 for $\mathrm{HN}$ to 0.95 for OI. Among partial components of morphology the $r_{G}$ were generally moderate to intermediate. In particular, OI had strong $r_{G}$ with all the partial components, especially HN, as well as with FS. The HW had low correlations with all partial scores, with the exception of SW and CT, where the $r_{G}$ was about 0.6.

The $r_{G}$ and $r_{P}$ estimates obtained in a multivariate analysis including all 10 traits are shown in Supplementary Table 1 . These estimates were close to the ones from the bivariate analyses, such that differences between results obtained by the two methods, expressed in absolute value, did not exceed 0.022 for $h^{2}, 0.03$ for $r_{P}$ and 0.09 for $r_{G}$.

The estimated genetic correlations between morphology/gaits and functional traits (Table 7) indicate that, with the only exception of the relationship of LE with working equitation maneability trial, all the correlations between morphology and functionality are positive, and there is a stronger relationship between morphological traits and the performance in working equitation dressage trial when 
Table 5

Estimated genetic $\left(\hat{\sigma}_{a}^{2}\right)$, permanent environmental $\left(\hat{\sigma}_{p e}^{2}\right)$ and phenotypic $\left(\hat{\sigma}_{p}^{2}\right)$ variances, and estimated heritability $\left(h^{2}\right)$, proportional contribution of permanent environmental effects $\left(c^{2}\right)$ and repeatability $\left(r_{e}\right)$ with corresponding standard error (SE) for functional traits in Lusitano horses.

\begin{tabular}{lrrrrr}
\hline Trait & $\hat{\sigma}_{a}^{2}$ & $\hat{\sigma}_{p e}^{2}$ & $\hat{\sigma}_{p}^{2}$ & $h^{2} \pm \mathrm{SE}$ & $r_{e} \pm \mathrm{SE}$ \\
\hline Working equitation dressage trial & 17.5241 & 19.6520 & 55.5875 & $0.32 \pm 0.171$ & $0.35 \pm 0.161$ \\
Working equitation maneability trial & 16.3052 & 24.9479 & 90.0750 & $0.18 \pm 0.121$ & $0.28 \pm 0.114$ \\
Classical dressage & 6.8317 & 5.9901 & 21.2293 & $0.32 \pm 0.075$ & $0.28 \pm 0.068$ \\
\hline
\end{tabular}

Table 6

Estimated genetic (above diagonal) and phenotypic (below diagonal) correlations for morphology and gaits traits in Lusitano horses, obtained in bivariate analyses. $^{a}$

\begin{tabular}{|c|c|c|c|c|c|c|c|c|c|c|}
\hline Trait & $\mathrm{HN}$ & SW & $\mathrm{CT}$ & $\mathrm{BL}$ & $\mathrm{CR}$ & $\mathrm{LE}$ & OI & GA & FS & HW \\
\hline Head and neck (HN) & - & 0.179 & 0.081 & 0.138 & 0.245 & 0.200 & 0.767 & 0.344 & 0.558 & -0.079 \\
\hline Shoulder and withers (SW) & 0.271 & - & 0.742 & 0.480 & 0.083 & 0.272 & 0.512 & 0.499 & 0.641 & 0.618 \\
\hline Chest and thorax (CT) & 0.217 & 0.400 & - & 0.694 & 0.522 & 0.505 & 0.655 & 0.610 & 0.810 & 0.549 \\
\hline Back and loin (BL) & 0.207 & 0.291 & 0.382 & - & 0.501 & 0.333 & 0.683 & 0.345 & 0.739 & 0.211 \\
\hline Croup (CR) & 0.273 & 0.195 & 0.304 & 0.347 & - & 0.506 & 0.566 & 0.364 & 0.649 & 0.029 \\
\hline Legs (LE) & 0.208 & 0.209 & 0.250 & 0.242 & 0.299 & - & 0.559 & 0.515 & 0.650 & 0.058 \\
\hline Overall impression (OI) & 0.568 & 0.374 & 0.392 & 0.446 & 0.455 & 0.368 & - & 0.643 & 0.949 & 0.096 \\
\hline Gaits (GA) & 0.304 & 0.328 & 0.319 & 0.301 & 0.296 & 0.337 & 0.398 & - & 0.773 & 0.157 \\
\hline Final score (FS) & 0.594 & 0.562 & 0.601 & 0.657 & 0.606 & 0.592 & 0.798 & 0.678 & - & 0.256 \\
\hline Height at withers (HW) & 0.049 & 0.293 & 0.221 & 0.131 & 0.062 & 0.038 & 0.113 & 0.104 & 0.189 & - \\
\hline
\end{tabular}

a Standard errors of genetic correlations ranged between 0.013 and 0.099 .

Table 7

Estimated genetic correlations between morphology/gaits and functional traits in Lusitano horses.

\begin{tabular}{llll}
\hline Morphological traits & \multicolumn{2}{l}{ Functional traits } \\
\cline { 2 - 4 } & $\begin{array}{l}\text { Working } \\
\text { equitation } \\
\text { dressage } \\
\text { trial }\end{array}$ & $\begin{array}{l}\text { Working } \\
\text { equitation } \\
\text { maneability } \\
\text { trial }\end{array}$ & $\begin{array}{l}\text { Classical } \\
\text { dressage }\end{array}$ \\
& & & \\
\hline Head and neck (HN) & 0.56 & 0.61 & 0.07 \\
Shoulder and withers (SW) & 0.50 & 0.25 & 0.57 \\
Chest and thorax (CT) & 0.54 & 0.23 & 0.42 \\
Back and loin (BL) & 0.44 & 0.24 & 0.20 \\
Croup (CR) & 0.49 & 0.04 & 0.19 \\
Legs (LE) & 0.36 & -0.17 & 0.23 \\
Overall impression (OI) & 0.80 & 0.40 & 0.27 \\
Gaits (GA) & 0.72 & 0.60 & 0.60 \\
Final score (FS) & 0.67 & 0.33 & 0.52 \\
Height at withers (HW) & 0.06 & -0.10 & 0.40 \\
\hline
\end{tabular}

a Standard errors of genetic correlations with working equitation dressage trial and working equitation maneability trial ranged between 0.059 and 0.233 ; standard errors of genetic correlations with classical dressage ranged between 0.045 and 0.134 .

compared with performance in maneability trial or classical dressage. For HW, there was a moderate $r_{G}(0.40)$ with performance in classical dressage, but the genetic correlations with the working equitation trials were very small (0.06 and -0.10). The FS and OI had moderate to strong genetic relationships with functional traits, especially with working equitation dressage trial, while GA had a strong $\mathrm{r}_{\mathrm{G}}$ with performance in all the disciplines, ranging from 0.60 to 0.72 . For partial conformation scores, the stronger genetic relationship with performance in maneability was observed for $\mathrm{HN}\left(r_{G}=0.61\right)$, while for classical dressage the stronger correlation was with $\mathrm{SW}\left(r_{G}=0.57\right)$. For working equitation dressage trial, the genetic correlations with partial conformation scores were all moderate to high, ranging from 0.36 to 0.56 .

The possibility of selecting indirectly for functionality based on earlier selection for morphology/gaits was assessed, considering either the information provided by final score or an index combining the various partial conformation scores, and the corresponding results are in Table 8. In the case of direct selection for functional traits considering only one record, the accuracy of selection obtained would be similar for WE dressage trial and classical dressage (about 0.56), and slightly lower for maneability (0.43). With index selection for conformation, the accuracies obtained with the different indexes tended to be low, such that in the case of indirect selection for final score, the relative efficiency obtained in the improvement of functionality would be about one-half when WE dressage trial is the target and nearly one-third for WE maneability trial and classical dressage (Table 8). An optimum selection index combining the different partial scores would be better than selection for final score in all cases (Table 8), especially if the selection goal is maneability, where the accuracy of selection increased to 0.376 , i.e., almost 3 times higher than the accuracy obtained with indirect selection for final score. Overall, the accuracy of a selection index combining partial morphological scores would not be as good as direct selection for functional traits, but the relative efficiency of indirect selection, assessed by the ratio between the accuracy reached with indirect and direct selection, was about 0.9 in selection for WE maneability trial, and about 0.7 for classical dressage and working equitation dressage trial.

The selection index weights computed for the different items reflecting conformation, when selection is intended to improve functional traits, are in Table 9. To assess the 
relative importance of each partial conformation item, Table 9 also includes the index weights per unit of genetic standard deviation of the conformation items, as well as the relative loss in accuracy of index selection if each trait is individually removed from the index. With the exception of HW, the partial morphology/gaits item consistently receiving more weight when selection was intended to

\section{Table 8}

Accuracy of selection $\left(r_{A P}\right)$, relative efficiency compared to direct selection (REF) and variance of the selection index $\left(\sigma_{I}^{2}\right)$ considering direct selection for functional traits, indirect selection for final score or selection based on an index of morphology components, when the selection goal is working equitation dressage trial, maneability trial or classical dressage.

\begin{tabular}{|c|c|c|c|}
\hline \multirow[t]{2}{*}{ Selection criteria } & \multicolumn{3}{|l|}{ Selection goal } \\
\hline & $\begin{array}{l}\text { Working } \\
\text { equitation } \\
\text { dressage trial }\end{array}$ & $\begin{array}{l}\text { Working } \\
\text { equitation } \\
\text { maneability trial }\end{array}$ & $\begin{array}{l}\text { Classical } \\
\text { dressage }\end{array}$ \\
\hline \multicolumn{4}{|l|}{ Direct selection } \\
\hline$r_{A P}$ & 0.562 & 0.426 & 0.567 \\
\hline \multicolumn{4}{|c|}{ Indirect selection for final score } \\
\hline$r_{A P}$ & 0.280 & 0.138 & 0.217 \\
\hline REF & 0.499 & 0.325 & 0.384 \\
\hline \multicolumn{4}{|c|}{ Index selection for morphological traits } \\
\hline$\sigma_{I}^{2}$ & 2.408 & 2.303 & 1.046 \\
\hline$r_{A P}$ & 0.371 & 0.376 & 0.391 \\
\hline REF & 0.660 & 0.883 & 0.690 \\
\hline
\end{tabular}

improve functionality was GA, followed by OI in working equitation dressage trial and $\mathrm{HN}$ in maneability. When the index weights are considered per genetic standard deviation, HW receives a strong positive weight in selection for classical dressage, and a strong negative weight in selection for maneability, but is not so important in selection for working equitation dressage trial. The potential loss in accuracy resulting from excluding a given trait from the selection index indicates that $\mathrm{HW}$ is the major trait to retain when selection is for classical dressage, and the second most important trait is GA. The GA was also the major trait to be retained in selection for both working equitation dressage and maneability trials, followed by $\mathrm{OI}$ for the former and HN for the latter functional traits.

\section{Discussion}

As a member of the Iberian-type horse, Lusitano is one of the oldest horse breeds in the world, and has contributed to the formation of different breeds worldwide, especially in the Americas (Luis et al., 2007), but also in different European countries, where it was historically valued for its strength and elegance (Bowling and Ruvinsky, 2000). For several centuries, Lusitano horses were selected not only for morphology and gaits, but also for functional aspects which reflect their specific uses, thus remaining a multi-purpose breed (Gonzaga, 2004; Loch,

Table 9

Vector of selection index weights, standardized index weights and relative percentage loss in accuracy of index selection if the trait is removed from the index, when the selection goal is working equitation dressage trial, working equitation maneability trial or classical dressage.

\begin{tabular}{|c|c|c|c|c|}
\hline \multirow[t]{2}{*}{ Item } & \multirow[t]{2}{*}{ Trait in index } & \multicolumn{3}{|l|}{ Selection goal } \\
\hline & & $\begin{array}{l}\text { Working equitation } \\
\text { dressage trial }\end{array}$ & $\begin{array}{l}\text { Working equitation } \\
\text { maneability trial }\end{array}$ & Classical dressage \\
\hline \multirow[t]{9}{*}{ Vector of selection index weights } & Head and neck & 0.4151 & 1.2341 & -0.2347 \\
\hline & Shoulder and withers & 0.2130 & 0.0923 & 0.3495 \\
\hline & Chest and thorax & 0.2990 & 0.1674 & 0.0690 \\
\hline & Back and loin & 0.0726 & 0.2944 & -0.1440 \\
\hline & Croup & 0.2405 & -0.5258 & 0.0257 \\
\hline & Legs & -0.5237 & -1.0694 & -0.1124 \\
\hline & Overall impression & 1.0119 & 0.0100 & 0.0457 \\
\hline & Gaits & 1.1811 & 1.3838 & 0.8218 \\
\hline & Height at withers & -0.0171 & -0.1238 & 0.1870 \\
\hline \multirow[t]{9}{*}{ Vector of standardized index weights ${ }^{\mathrm{a}}$} & Head and neck & 0.133 & 0.394 & -0.075 \\
\hline & Shoulder and withers & 0.046 & 0.020 & 0.076 \\
\hline & Chest and thorax & 0.063 & 0.035 & 0.014 \\
\hline & Back and loin & 0.019 & 0.078 & -0.038 \\
\hline & Croup & 0.062 & -0.136 & 0.007 \\
\hline & Legs & -0.083 & -0.169 & -0.018 \\
\hline & Overall impression & 0.245 & 0.002 & 0.011 \\
\hline & Gaits & 0.337 & 0.395 & 0.234 \\
\hline & Height at withers & -0.051 & -0.369 & 0.557 \\
\hline \multirow{9}{*}{$\begin{array}{l}\text { Relative loss in selection } \\
\text { accuracy (\%) }\end{array}$} & Head and neck & 6.7 & 29.1 & 2.4 \\
\hline & Shoulder and withers & 1.1 & 0.1 & 3.7 \\
\hline & Chest and thorax & 2.3 & 0.3 & 0.2 \\
\hline & Back and loin & 0.2 & 1.3 & 0.8 \\
\hline & Croup & 1.9 & 4.7 & 0.0 \\
\hline & Legs & 8.7 & 17.1 & 0.5 \\
\hline & Overall impression & 21.0 & 0.0 & 0.0 \\
\hline & Gaits & 57.9 & 37.6 & 31.7 \\
\hline & Height at withers & 0.3 & 9.8 & 60.8 \\
\hline
\end{tabular}

${ }^{a}$ Index weight standardized per genetic standard deviation. 
1986). Even though Lusitano horses continue to be attached mostly to leisure activities and mounted bullfighting, in recent years they have occupied an important share of the breeds represented in major horse competitions, e.g., in working equitation (WAWE, 2013b), four-inhand driving (Cowdery, 2006), and dressage in world championships and the Olympic Games (Appels, 2008; Warne, 2012).

The breeding program of the Lusitano horse emphasizes the adherence to the breed standard, morphological features and gaits (APSL, 2010), but so far results from competition events have not been taken into account in the selection program and no specific genetic evaluation has been performed. Our study is the first comprehensive analysis of pedigree, morphology/gaits and functional data collected in Lusitano horses over more than 40 years, and provides information which is essential for the design of the selection program and the development of a routine genetic evaluation system that can supply objective information to breeders.

The benefits of organized breeding programs have been assessed for several horse breeds (Dubois et al., 2008; Jaitner and Reinhardt, 2003; Kearsley et al., 2008; Posta et al., 2009), and the possibility has been suggested of harmonizing selection programs across different breeds and countries with the same breeding objectives (Bruns et al., 2004; Koenen and Aldridge, 2002). In the particular case of Lusitano horses, the definition of breeding objectives is not an easy task, because selection is aimed at multiple purposes and both morphology/gaits and functional traits should be taken into account. Therefore, morphology-type may be regarded as having a double role in selection of Lusitano horses, as it represents a breeding objective by itself and also because of its relationship with functional traits.

The estimated heritability reported for conformation traits in other horse breeds tends to be high for body dimensions, low for leg stances and moderate for other morphological traits (see reviews by Saastamoinen and Barrey, 2000; Stock and Distl, 2006). For example, the heritability of height at withers has been reported to be 0.88 in Thoroughbreds above one year of age (Hintz et al., 1978), 0.20 in the Dutch Warmblood (Koenen et al., 1995), 0.79 in the Haflinger breed (Miglior et al., 1998), 0.73 in Norwegian Cold-blooded Trotters (Dolvik and Klemetsdal, 1999), 0.59 in the Andalusian horse (Molina et al., 1999), 0.47 in the Mangalarga breed (Mota et al., 2006), 0.67 in Austrian Noriker draught horse (Druml et al., 2008) and 0.34 in the Belgian warmblood horse (Rustin et al., 2009). For morphological partial scores, heritability estimates for leg stances are generally in the range of 0.08 (Druml et al., 2008; Saastamoinen et al., 1998; Thoren Hellsten et al., 2009) and 0.29 (Molina et al., 1999), while for overall type impression the heritability estimates are usually between about 0.20 (Christmann et al., 1995) and 0.30 (Albertsdottir et al., 2008). The heritability of gaits and movements may differ for walk, trot and canter (Albertsdottir et al., 2008), but the overall gaits score generally has an estimated heritability of about 0.15-0.20 (Molina et al., 1999; Preisinger et al., 1991; Saastamoinen et al., 1998). Our estimated heritabilities of 0.61 for HW, 0.07 for LE, 0.14 for OI and 0.17 for GA are generally in the range reported in the literature, even though higher estimates have been reported for conformation traits in Hanoverian Warmblood horses (Stock and Distl, 2006). As expected, our results confirm a much higher genetic variability for linear measurements than for conformation scores (Saastamoinen and Barrey, 2000).

The nature of the current grading system used to evaluate morphology and gaits in Lusitano horses could lead to an increase in environmental variability, given the difficulties inherent to the judgment of a subjective trait (even though the judges are trained and experienced) and the fact that the scoring scale has not been applied uniformly to the different traits, with a wider scale of variation for HN and lower for SW. Moreover, a final score resulting from the weighted sum of the partial morphological scores is highly dependent on the scale used when they are judged and classified, as detected in our path analysis (Table 2), which disclosed discrepancies between the expected and realized weights given to each partial grade. One possibility of improving the accuracy of selection for morphology and gaits would be to adopt a linear scoring system in which the traits, rather than being scored on their desirability, are evaluated in a continuous scale that corresponds to their expression between two biological extremes, which has much better distribution properties (Rustin et al., 2009; Samoré et al., 1997). Also, new approaches in judging horse dynamics, including detailed movement evaluations and the assessment of impaired balance (Becker et al., 2013) may be helpful in selection for improved gaits performance.

All the morphological scores were positively correlated with each other, with genetic correlations which were generally higher than those observed in Andalusian horses (Molina et al., 1999), perhaps reflecting differences in the scoring system applied. It should be noticed that gaits had strong positive correlations with $\mathrm{OI}, \mathrm{CT}$ and LE, reflecting that horses which are closer to the breed standard, more harmonious and with good leg stances, have better gaits, expressed as paces with more freedom, elasticity and regularity (FEI, 2013). The only noticeable genetic correlations of HW were with SW and CT, which largely reflect the depth of the horse and thus its body size. The genetic correlations of HW with all the other morphological traits were small, implying that body size and morphology or beauty are essentially independent in Lusitano horses, a pattern which is opposite to that found in the Austrian Noriker draught horse, where HW and morphology partial scores have strong correlations (Druml et al., 2008).

In what concerns functionality, the heritability estimates for performance in dressage events reported in the literature usually range between 0.1 and 0.3 (Ricard et al., 2000; Stewart et al., 2010; Thoren Hellsten et al., 2009), in line with our estimate of 0.32 for dressage score. To our knowledge, genetic parameters for working equitation have not been reported so far, but our estimate of heritability for the dressage trial $(0.32)$ is identical to that obtained for classical dressage. For maneability, however, the estimated heritability is lower ( 0.18 in our study), possibly because this type of trial takes place in a track with different obstacles, and the horse must show its versatility when faced with different challenges, including jumping, slalom, opening a gate, etc. Thus, even though the 
maneability trial is more complex than showjumping, our heritability estimate is close to that reported for the score in this discipline (Aldridge et al., 2000; Ricard et al., 2000). Moreover, the higher genetic variance estimated for working equitation disciplines when compared with dressage would indicate that, for Lusitano horses in comparable circumstances, selection for working equitation should be more successful than selection for classical dressage.

Until now, information is scarce on the genetic relationships existing between morphology and dressage ability in horses, and there are no estimates available for the relationships with performance in working equitation. The few estimates that have been reported until now point towards a low to medium genetic correlation between morphological traits and performance in dressage events (Koenen et al., 1995; Wallin et al., 2003), with the exception of gaits, which have a stronger genetic correlation with dressage ability (Ducro et al., 2007; Olsson et al., 2008; Wallin et al., 2003). Nevertheless, as functional traits in horses are generally measured at a more advanced age, it has been argued that, in spite of the modest genetic correlations that they may have, morphological traits can be used as an early culling criterion when selection is intended to improve dressage performance (Saastamoinen and Barrey, 2000).

The results of our analyses are based on a large number of records for morphology, but the information available for functional traits is more scarce, thus the estimated genetic correlations have appreciable standard errors. Nevertheless, our preliminary study indicates that, in general, there is no antagonism between conformation and performance, which is of particular relevance in Lusitano horses, where both groups of traits represent important breeding objectives. In this study, with the exception of $\mathrm{HW}$, all morphological traits had strong genetic correlations with the dressage trial of working equitation (between 0.36 and 0.80 , Table 7) and, to some extent, with performance in classical dressage (0.07-0.60, Table 7$)$. For WE maneability trial, on the other hand, the genetic correlations with morphology were generally smaller, and even negative in the case of LE. Consistently, GA had a strong genetic correlation with performance in all disciplines, in agreement with results reported for dressage in several other breeds (Ducro et al., 2007; Olsson et al., 2008; Wallin et al., 2003). On the other hand, HW had an important positive relationship with performance in classical dressage (0.40), in contrast with the estimated genetic correlation of -0.05 reported by Koenen et al. (1995), but the correlation was very small with the results of both maneability $(-0.10)$ and dressage (0.06) trials in WE.

One possibility of selecting for functional ability in Lusitano horses would be to implement a two-stage selection system, where horses are initially culled based on their morphological features, as it has been suggested for other horse breeds (Ducro et al., 2007; Holmstrom et al., 1990), with a second selection stage applied later on, determined by the performance of the horse in equestrian events. The expected efficiency of this indirect selection can be appraised from the selection accuracy achieved, but it should also be considered that indirect selection could take place at an earlier age (thus reducing the generation interval) while direct selection for functionality can be based on multiple records of the individual (thus increasing the accuracy of selection), and in both cases family information could also be taken into account. In our study, if early selection was based on final score, the corresponding accuracy of indirect selection for functional traits was low (ranging from about 0.14 to 0.28 ) such that the efficiency of selection would be at best one-half of that achieved if direct selection was practiced. The correlated response could be much better if selection was based on an index assigning appropriate weights to each morphological item, in which case indirect selection would result in improvement of all functional traits, especially maneability, with an accuracy which was almost as high as that obtained with direct selection. In the long run, if selection for functional traits is the major goal, the optimum approach would be to predict breeding values for working equitation and dressage with a multi-trait AM, including conformation, gaits and performance results. In these analyses, information for the various traits on all relatives could be incorporated, and weighted appropriately in the mixed model used in prediction of breeding values for each functional trait, thus enhancing selection response.

An important issue in a multi-purpose breed such as Lusitano is the assessment of how good the agreement is between the weights given to individual morphology items if different functional traits are considered as the final breeding goal, i.e., if a different type of horse is more suitable for a given discipline (Barrey et al., 2002). In our study, there were differences between the relative importance given to a specific morphological item if the horse was intended to be further selected for WE dressage and maneability trials or for classical dressage. Specifically, when considered in standardized units, gaits were always among the two most important partial items in the index if selection was for any of the equestrian disciplines considered here, which is in line with the results reported by Olsson et al. (2000) for Swedish Warmblood horses. Height at withers, on the other hand, had a positive weight when the selection goal was classical dressage and a negative weight if improvement was intended in WE maneability trial. This could reflect the characteristics desirable in either one of the disciplines, because in classical dressage a horse is expected to have paces with wider amplitude and these are easier to perform by taller horses (Holmstrom et al., 1990), while in maneability a shorter horse is easier to collect itself and performs better when turning around between obstacles or facing other challenges in a course (Currie, 1997). The loss in accuracy if one morphological item is left out of the index basically reflects these same aspects, such that gaits are the most important trait to be included in working equitation, followed by overall impression if the goal is improving the dressage trial component, and head and neck if the objective is the maneability trial. If the intention is to select indirectly for performance in classical dressage, then the index must include primarily height at withers and gaits, as all the other morphological traits are of minor importance.

This study is the first appraisal of the existing genetic variability and relationships for morphology, gaits and functionality in the Lusitano horse breed, and the 
parameters estimated here can be used to refine the breeding program and develop a systematic genetic evaluation platform (Dubois et al., 2008). Our results indicate that, in spite of its demographic bottlenecks (Vicente et al., 2012), the Lusitano still maintains considerable levels of genetic variability for those traits, and that there is no antagonism between them. The inclusion of morphological traits in the selection goal of Lusitano is justified by the history of the breed, where beauty and elegance have always played a key-role, and the estimated heritabilities make selection for these traits feasible. In addition, given the favorable genetic relationships existing between morphology and performance, morphological traits can play an important role in a two-stage selection program aimed at improving working equitation or classical dressage, which are disciplines where the Lusitano is becoming more popular worldwide. However, given the specific nature and magnitude of the existing genetic relationships of morphology with each of the functional traits studied, it may be judicious to consider the possibility of developing and maintaining specialized lines within the Lusitano breeding program. The tremendous opportunities arising from the incorporation of genomic information in the selection program of Lusitano should also be investigated, as their contribution in reducing generation interval and enhancing selection accuracy could result in extraordinary benefits in terms of genetic progress (Haberland et al., 2012).

Overall, our results indicate that, given the existing levels of genetic variability, selection for conformation, gaits and functional traits is feasible in the Lusitano horse breed. The favorable genetic relationships existing between morphology and performance indicate that morphology/gaits traits can be used as an early selection criterion, to enhance genetic improvement for working equitation and classical dressage, which are gaining importance as selection goals in Lusitano horses.

\section{Conflict of interest statement}

The authors report that there are no conflicts of interest relevant to this publication.

\section{Acknowledgments}

The authors wish to express thanks to Fundação Alter Real, Associação Portuguesa de Criadores do Cavalo PuroSangue Lusitano (APSL) and Federação Equestre Portuguesa (FEP) for providing the data used in this study.

\section{Appendix A. Supporting information}

Supplementary data associated with this article can be found in the online version at http://dx.doi.org/10.1016/j. livsci.2014.01.020.

\section{References}

Albertsdottir, E., Eriksson, S., Nasholm, A., Strandberg, E., Arnason, T., 2008. Genetic correlations between competition traits and traits scored at breeding field-tests in Icelandic horses. Livest. Sci. 114 $181-187$.

Aldridge, L.I., Kelleher, D.L., Reilly, M., Brophy, P.O., 2000. Estimation of the genetic correlation between performances at different levels of show jumping competitions in Ireland. J. Anim. Breed. Genet. 117, $65-72$.

Appels, A., 2008. Brazil Qualifies Team for 2008 Olympic Games in Hong Kong 〈http://www.eurodressage.com/equestrian/2008/06/29/brazilqualifies-team-2008-olympic-games-hong-kong $\rangle$ (acessed 05.04.13).

APSL, 2010. Studbook Regulation. Associação Portuguesa de Criadores do Cavalo Puro-sangue Lusitano. Cascais, Portugal.

Barrey, E., Desliens, F., Poirel, D., Biau, S., Lemaire, S., Rivero, J.L.L., Langlois, B., 2002. Early evaluation of dressage ability in different breeds. Equine Vet. J. (Suppl. 34), 319-324.

Becker, A.C., Stock, K.F., Distl, O., 2013. Correlations of unfavorable movement characteristics in warmblood foals and mares with routinely assessed conformation and performance traits. Animal 7, 11-21.

Boldman, K.G., Kriese, L.A., Van Vleck, L.D., Kachman, S.D., 1995. A Manual for Use of MTDFREML. USDA, ARS.

Bowling, A.T., Ruvinsky, A., 2000. Genetic aspects of domestication, breeds and their origins. In: Bowling, A.T., Ruvinsky, A. (Eds.), The Genetics of the Horse, CABI Publishing, Oxon, UK, pp. 25-52.

Bruns, E., Ricard, A., Koenen, E., 2004. Interstallion - on the way to an international genetic evaluation of sport horses. In: 55th EAAP. Session HG5. Slovenia.

Cameron, N.D., 1997. Selection Indices and Prediction of Genetic Merit in Animal Breeding. CAB International, Wallingford.

Christmann, L., Bruns, E., Schade, W., 1995. Survey on the mare performance test in the Hanoverian breed. In: Proceedings of the 46th EAAP, vol. 3551. Prague.

Cowdery, A., 2006. Brasseur Claims World Driving Gold 〈http://www. horseandhound.co.uk/weg-2006/driving/article.php?id=93998> (acessed 05.04.13)

Currie, A., 1997. The Western performance horse. Proc. AAEP 43, 46-48.

Dolvik, N.I., Klemetsdal, G., 1999. Conformational traits of Norwegian Cold-blooded Trotters: heritability and the relationship with performance. Acta Agric. Scand. 49, 156-162.

Druml, T., Baumung, R., Solkner, J., 2008. Morphological analysis and effect of selection for conformation in the Noriker draught horse population. Livest. Sci. 115, 118-128.

Dubois, C., Manfredi, E., Ricard, A., 2008. Optimization of breeding schemes for sport horses. Livest. Sci. 118, 99-112.

Ducro, B.J., Koenen, E.P.C., Van Tartwijk, J.M.F.M., Bovenhuis, H., 2007. Genetic relations of movement and free-jumping traits with dressage and show-jumping performance in competition of Dutch Warmblood horses. Livest. Sci. 107, 227-234.

Falconer, D.S., MacKay, T.F.C., 1996. Introduction to Quantitative Genetics, 4th ed. Longmans Green, Essex, UK..

FEI, 2013. Dressages Rules. Fédération Equestre Internationale, Lausanne, Switzerland.

Gonzaga, P.G., 2004. A History of the Horse: The Iberian Horse from Ice Age to Antiquity, vol. I. J.A. Allen, UK.

Groeneveld, E., Kovac, M., Mielenz, N., 2010. VCE: User's Guide and Reference Manual. Version 6.0.

Haberland, A.M., Konig von Borstel, U., Simianer, H., Konig, S., 2012. Integration of genomic information into sport horse breeding programs for optimization of accuracy of selection. Animal 6, 1369-1376.

Hazel, L.N., 1943. The genetic basis for constructing selection indexes. Genetics 28, 476-490.

Hintz, R.I., Hintz, H.F., Van Vleck, L.D., 1978. Estimation of heritabilities for weight, height and front cannon bone circumference of Thoroughbreds. J. Anim. Sci. 6, 1243-1245.

Holmstrom, M., Magnusson, L.E., Philipsson, J., 1990. Variation in conformation of Swedish Warmblood horses and conformational characteristics of elite sport horses. Equine Vet. J. 22, 186-193.

Jaitner, J., Reinhardt, F., 2003. National genetic evaluation for horses in Germany. In: 54th Annual Meeting of the European Association for Animal Production. Comission on Horse Production, Session H4, Rome, Italy.

Kearsley, C.G.S., Woolliams, J.A., Coffey, M.P., Brotherstone, S., 2008. Use of competition data for genetic evaluations of eventing horses in Britain: analysis of dressage, showjumping and cross country phases of eventing competition. Livest. Sci. 118, 72-81.

Koenen E.P.C., Aldridge, L.I., 2002. Testing and genetic evaluation of sport horses in an international perspective. In: 7th World Congress Applied to Livestock Production, Montpellier, France.

Koenen, E.P.C., Van Veldhuizen, A.E., Brascamp, E.W., 1995. Genetic parameters of linear scored conformation traits and their relation 
to dressage and showjumping performance in the Dutch Warmblood Riding Horse population. Livest. Prod. Sci. 43, 85-94.

Li, C.C., 1975. Path Analysis. A Primer. The Boxwood Press, Pacific Grove, California.

Loch, S., 1986. The Royal Horse of Europe: The Story of the Andalusian and Lusitano. J.A. Allen \& Co Ltd., UK.

Luis, C., Juras, R., Oom, M., Cothran, E., 2007. Genetic diversity and relationships of Portuguese and other horse breeds based on protein and microsatellite loci variation. Anim. Genet. 38, 20-27.

Miglior, F., Pagnacco, G., Samore, A.B., 1998. A total merit index for the Italian Haflinger horse using breeding values predicted by a multitrait animal model. In: Proceedings of the 6th WCGALP, vol. XXIV, Armidale, Australia, pp. 416-419.

Molina, A., Valera, M., Santos, R., Rodero, A., 1999. Genetic parameters of morphofunctional traits in Andalusian horse. Livest. Prod. Sci. 60, 295-303.

Mota, M.D.S., Prado, R.S.A., Ferreira, D.F.M.G., 2006. Estimativa de parâmetros genéticos para o deslocamento em cavalos da raça Mangalarga. Arch. Zootec 55, 207-210.

Olsson, E., Nasholm, A., Strandberg, E., Philipsson, J., 2008. Use of field records and competition results in genetic evaluation of station performance tested Swedish Warmblood stallions. Livest. Sci. 117, 287-297.

Olsson, E.G., Arnason, T., Nasholm, A., Philipsson, J., 2000. Genetic parameters for traits at performance test of stallions and correlations with traits at progeny tests in Swedish warmblood horses. Livest. Prod. Sci. 65, 81-89.

Posta, J., Komlósi, I., Mihók, S., 2009. Breeding value estimation in the Hungarian Sport Horse population. Vet. J. 181, 19-23.

Preisinger, R., Wilkens, J., Kalm, E., 1991. Estimation of genetic parameters and breeding values for conformation traits for foals and mares in the Trakehner population and their practical implications. Livest. Prod. Sci. 29, 77-86.

Ricard, A., Bruns, E., Cunningham, E.P., 2000. Genetics of performance traits. In: Bowling, A.T., Ruvinsky, A. (Eds.), The Genetics of the Horse, CABI Publishing, Oxon, UK, pp. 411-438.

Rustin, M., Janssens, S., Buys, N., Gengler, N., 2009. Multi-trait animal model estimation of genetic parameters for linear type and gait traits in the Belgian warmblood horse. J. Anim. Breed. Genet. 126, 378-386.

SAS Institute, 2004. SAS ${ }^{\circledR}$ 9.1.2 for Microsoft Windows. SAS International, Heidelberg.
Saastamoinen, M.T., Barrey, E., 2000. Genetics of conformation, locomotion and physiological traits. In: Bowling, A.T., Ruvinsky, A. (Eds.), The Genetics of the Horse, CABI Publishing, Oxon, UK, pp. 439-472.

Saastamoinen, M., Suontama, M., Ojala, M., 1998. Heritability of conformation traits and their relationships to racing performance in the Finnhorse Trotter. In: Proceedings of the 6th WCGALP, Armidale, Australia.

Samoré, A.B., Pagnacco, G., Miglior, F., 1997. Genetic parameters and breeding values for linear type traits in the Haflinger horse. Livest. Prod. Sci. 52, 105-111.

Sánchez, M.J., Gómez, M.D., Peña, F., Monterde, J.G., Morales, J.L., Molina, A., Valera, M., 2013. Relationship between conformation traits and gait characteristics in Spanish Purebred Horses. Archiv. Tierz. 56, 13.

Stewart, I.D., Woolliams, J.A., Brotherstone, S., 2010. Genetic evaluation of horses for performance in dressage competitions in Great Britain. Livest. Sci. 128, 36-45.

Stock, K.F., Distl, O., 2006. Genetic correlations between conformation traits and radiographic findings in limbs of German Warmblood riding horses. Genet. Sel. Evol. 38, 657-671.

Thoren Hellsten, E., Jorjani, H., Philipsson, J., 2009. Genetic correlations between similar traits in the Danish and Swedish Warmblood sport horse populations. Livest. Sci. 124, 15-20.

Van Vleck, L.D., 1993. Selection Index and Introduction to Mixed Model Methods. CRC Press, Boca Raton, USA.

Vicente, A.A., Carolino, N., Gama, L.T., 2012. Genetic diversity in the Lusitano horse breed assessed by pedigree analysis. Livest. Sci. 148 $16-25$.

Wallin, L., Strandberg, E., Philipsson, J., 2003. Genetic correlations between field results of Swedish Warmblood Riding Horses as 4years-old and lifetime performance results in dressage and show jumping. Livest.Prod. Sci. 82, 61-71.

Warne, S., 2012. Goncalo Carvalho and Rubi Danced with the Stars at 2012 Olympic Games 〈http://www.eurodressage.com/equestrian/ 2012/09/30/goncalo-carvalho-and-rubi-danced-stars-2012-olympicgames> (acessed 05.04.13).

WAWE, 2013a. International Working Equitation Regulations. World Association for Working Equitation.

WAWE, 2013b. International Events History 〈http://www.wawe-official.com/ working-equitation/international-events-history $\rangle$ (acessed 05.04.13). 